\title{
TU/e EmonOWEN

\section{Development of an on-line analyzer for organic anaesthetics in inspiratory and end-tidal gases}

\section{Citation for published version (APA):}

Cramers, C. A. M. G., \& Trimbos, H. F. (1976). Development of an on-line analyzer for organic anaesthetics in inspiratory and end-tidal gases. Journal of Chromatography, 119(1), 71-84. https://doi.org/10.1016/S00219673(00)86771-0

DOI:

10.1016/S0021-9673(00)86771-0

Document status and date:

Published: 01/01/1976

\section{Document Version:}

Publisher's PDF, also known as Version of Record (includes final page, issue and volume numbers)

\section{Please check the document version of this publication:}

- A submitted manuscript is the version of the article upon submission and before peer-review. There can be important differences between the submitted version and the official published version of record. People interested in the research are advised to contact the author for the final version of the publication, or visit the $\mathrm{DOI}$ to the publisher's website.

- The final author version and the galley proof are versions of the publication after peer review.

- The final published version features the final layout of the paper including the volume, issue and page numbers.

Link to publication

\section{General rights}

Copyright and moral rights for the publications made accessible in the public portal are retained by the authors and/or other copyright owners and it is a condition of accessing publications that users recognise and abide by the legal requirements associated with these rights.

- Users may download and print one copy of any publication from the public portal for the purpose of private study or research.

- You may not further distribute the material or use it for any profit-making activity or commercial gain

- You may freely distribute the URL identifying the publication in the public portal.

If the publication is distributed under the terms of Article 25fa of the Dutch Copyright Act, indicated by the "Taverne" license above, please follow below link for the End User Agreement:

www.tue.nl/taverne

Take down policy

If you believe that this document breaches copyright please contact us at:

openaccess@tue.nl

providing details and we will investigate your claim. 
CHROM. 8962

\title{
DEVELOPMENT OF AN ON-LINE ANALYZER FOR ORGANIC ANAES- THETICS IN INSPIRATORY AND END-TIDAL GASES
}

\author{
C. A. CRAMERS and H. F. TRIMBOS
}

Department of Instrumental Analysis, Eindhoven University of Technology, Eindhoven (The Netherlands)

(First received November 5th, 1975; revised manuscript received December 15th, 1975)

\section{SUMMARY}

An analyzer for measuring the concentrations of volatile organic anaesthetic agents in inspiratory and end-tidal gases has been constructed. Respiratory gas from an anaesthetized patient is led continuously through a heated capillary transport tube (length $5.7 \mathrm{~m}$, I.D. $0.25 \mathrm{~mm}$ ) to a hydrogen flame-ionization detector. The pressure drop across the capillary tube necessary to transport the gas is applied by operating the detector at reduced pressure. The ionization current, caused by the organic anaesthetic agent in the detector, is measured with an electrometer amplifier. The transport time, at an optimal pressure drop of $600 \mathrm{~mm} \mathrm{Hg}$, is $4.3 \mathrm{sec}$, and the flow-rate of respiratory gas in the tube is then $3.9 \mathrm{ml} / \mathrm{min}$. The time constant of the system is 0.2 sec. It is shown that mixing between successive inspiratory and expiratory samples can be neglected.

The use of the system is demonstrated by two examples. Firstly, the end-tidal concentration of diethyl ether during the wash-out after a combined intravenous infusion-inhalation anaesthesia was measured. Secondly, the analyzer was used during experiments to measure the ventilation:perfusion ratio by administration of small concentrations of halothane.

\section{INTRODUCTION}

The condition of a patient during anaesthesia is determined to a large extent by the type and amount of the volatile anaesthetic agent administered. Measurement of the concentrations of anaesthetics in tissues, blood and respiratory gases may contribute to a better understanding of the pharmacokinetics and better control of anaesthesia.

The anaesthetic action depends upon the anaesthetic level in blood and therefore in tissues. So far, the methods available for measuring the concentration in blood are not completely satisfactory or are time consuming ${ }^{2}$. The analysis of anaesthetic agents in gases, however, is more straightforward. As the concentration in the alveoli is related to the level in arterial blood, measurement of the end-tidal concentration to indicate the anaesthetic condition is obvious. The techniques used for measuring 
the concentrations of organic anaesthetics in a gas phase are ultraviolet and infrared spectrometry, gas chromatography and mass spectrometry2. Up to now "respiration mass spectrometry" has been the preferred technique for analyzing respirations continuously, owing to the short scan time. The high costs of mass spectrometers, however, precludes their use in many instances.

In this paper, an instrument is described that has been developed to indicate continuously the concentration of organic anaesthetics in respiratory gases, thus avoiding the above disadvantage.

The main component of the analyzer is a hydrogen flame-ionization detector (FID). The ionization current, measured by an electrometer amplifier, is proportional to the amount of organic component that reaches the FID per unit time. The FID is sensitive only to the organic anaesthetic agent used and the inorganic components of respiratory gases (oxygen, carbon dioxide, nitrogen, nitrous oxide and water) will not be detected. This principle has already been used by Feinland $e t a l^{3}$ in the analysis of automotive exhaust gases.

During anaesthesia, usually only one organic anaesthetic agent is administered. In such instances there is no need to use a chromatographic separation column and the concentration of anaesthetic in inspiratory and expiratory gases can be directly measured with an FID. The transport of the gases to be analyzed to the detector is effected by operating the FID at reduced pressure (Fig. 1). The connection tube between the patient and the analyzer is a capillary tube so as to prevent mixing between successive samples in the "sample train". The time constant of the total system (transport tube, FID and electrometer) is such that concentration changes that occur in the expiratory gas samples can easily be monitored. As no separation column is used, only one anaesthetic can be determined at a time.

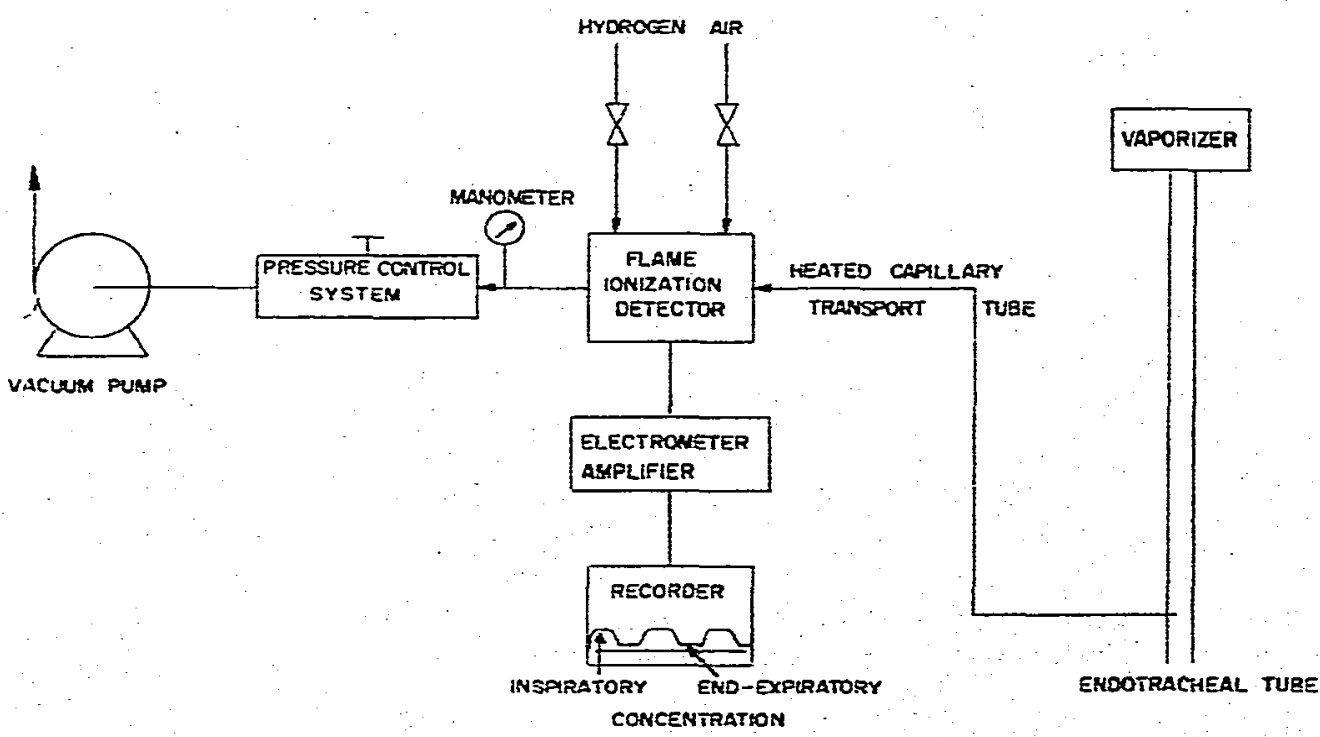

Fig. 1. Schematic diagram of the on-line analyzer. 


\section{INSTRUMENTAL}

An analyzer was constructed following the principles discussed above. It consists of three main components:

(1) A Pye Unicam flame-ionization detector. The necessary fiow-rates of hydrogen and air are kept constant by Becker pressure controllers and the flow-rates are indicated by Brooks rotameters. The applied polarization voltage is $170 \mathrm{~V}$. The ionization current is measured with a Pye Unicam ionization amplifier (Type 12304) and recorded on a Yokogawa recorder (Type 3047). The FID is placed in a stainlesssteel block, heated to $110^{\circ} \mathrm{C}$ by two electric heating rods ( $40 \mathrm{~W}$ each) in order to prevent condensation of water vapour in the detector.

(2) A stainless-steel capillary tube. A needle connected at one end is placed in the endotracheal tube during measurements. In order to prevent condensation of exhaled water vapour, the tube is directly heated to approximately $40^{\circ} \mathrm{C}$ by a direct current (12 V from a battery).

(3) An Edwards vacuum pump (Type RBF 3). This pump maintains a constant reduced pressure in the FID. Two small buffer vessels and a Negretti pressure controller are included in the vacuum system so as to prevent pressure fluctuations.

Fig. 2 shows the flame-ionization detector in detail. The instrument has to meet the following requirements if inspiratory and expiratory concentrations of organic anaesthetics have to be monitored continuously: the pressure drop across the capillary tube has to be kept constant in order to keep the flow-rate of respiration gas constant, so as to prevent variations in detector response; there should be negligible mixing of successive inspiratory and expiratory samples in the transport tube; the flow-rates of hydrogen and air have to be kept constant and adjusted to the optimal conditions in order to minimize variations in detector response (it appears that optimal flow-rates are dependent on the pressure in the FID); and the detector response should be linear in the concentration range of the anaesthetic under study.

\section{Flow of respiratory gases in the transport tube}

The properties of the analyzer are dependent to a large extent on the linear velocity of the respiratory gases in the transport tube. It appears that in all practical cases the flow of gas in the tube is laminar, and therefore the average velocity, $\bar{v}$, can be derived from Poisseuille's law:

$$
\bar{v}=\frac{d^{2} \Delta p}{32 \eta L}
$$

where $d(\mathrm{~m})$ is the diameter of the capillary tube, $\Delta p\left(\mathrm{~N} / \mathrm{m}^{2}\right)$ is the pressure drop across the capillary tube, $\eta\left(\mathrm{N} \cdot \mathrm{sec} / \mathrm{m}^{2}\right)$ is the viscosity of the gas and $L(\mathrm{~m})$ is the length of the tube. According to eqn. 1, the velocity depends on the dimensions of the tube, the reduced pressure in the detector and the viscosity and thus the composition of the transported gases.

In order to obtain a short time lag between sampling and detection of respiratory gases and to decrease mixing by molecular diffusion in the axial direction, the velocity has to be as large as possible. The velocity is restricted by the condition of linearity. An FID is a mass flow detector and, in the linear range, the signal is pro- 


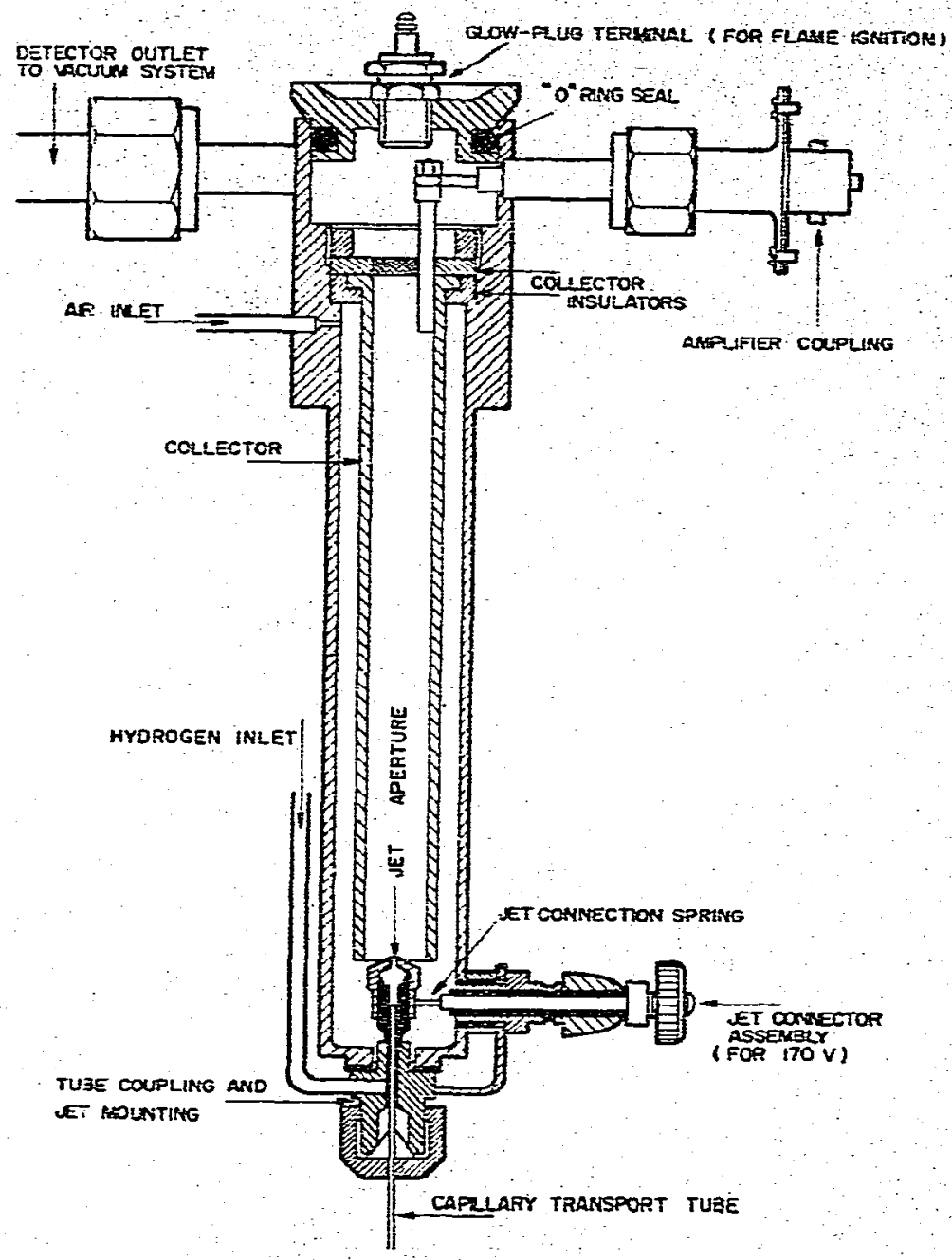

Fig. 2. The Pye Unicam flame-ionization detector.

portional to the mass How of organic compound that reaches the detector per unit time. The flow of anaesthetic agent to be analyzed has to be in this linear range, and this requirement leads to the use of a tube with a small diameter. It will be demonstrated below that a small diameter also reduces the mixing in the sample transport tube. In this work, a stainless-steel capillary tube of I.D. $0.25 \mathrm{~mm}$ with a length of $5.7 \mathrm{~m}$ is used. In this way, the analyzer could be operated outside the operating theatre.

The delay times at different pressures of the detector are measured and from these times the linear velocities are calculated. The relationship between the velocity and pressure drop is linear, according to Poisseuille's law. As mentioned before, the flow in the tube is laminar (at $\Delta p=650 \mathrm{~mm} \mathrm{Hg}, R e=60$ ). As the gas flow in the capillary tube increases with increasing pressure drop, the detector response should 
increase accordingly (mass flow detector). Signal yersus pressure drop curves are shown in Fig. 3. Although the flow is proportional to the pressure drop, the detector response clearly is not and another phenomenon must be involved. Obviously, the ionization efficiency of an FID depends on the absolute pressure in the detector. At a constant sample flow-rate, the response increases with decreasing pressure in the FID until a local maximum is reached ${ }^{45}$. The measured curves in Fig. 3 are the result of the infuence of both absolute pressure and gas flow on the deteetor response.-

Mixing in the capillary tube

A delta function injected at the inlet of a capillary tube broadens, owing to diffusion phenomena, into a Gaussian function at the outiet of the tube. In uncoated capiliary tubes, peak broadening by several diffusion phenomena can be described by eqn. 2, according to Golay ${ }^{6}$. Under laminar flow conditions:

$$
H=\frac{2 D_{g}}{\bar{v}}+\frac{d^{2} \bar{v}}{96 D_{g}}
$$

The two terms on the right-handside describe peak broadening due to molecular and Taylor diffusion, respectively. $D_{g}\left(\mathrm{~m}^{2} / \mathrm{sec}\right)$ is the diffusion coefficient of the anaesthetic in inspiratory or expiratory gas. From chromatographic theory, it follows that

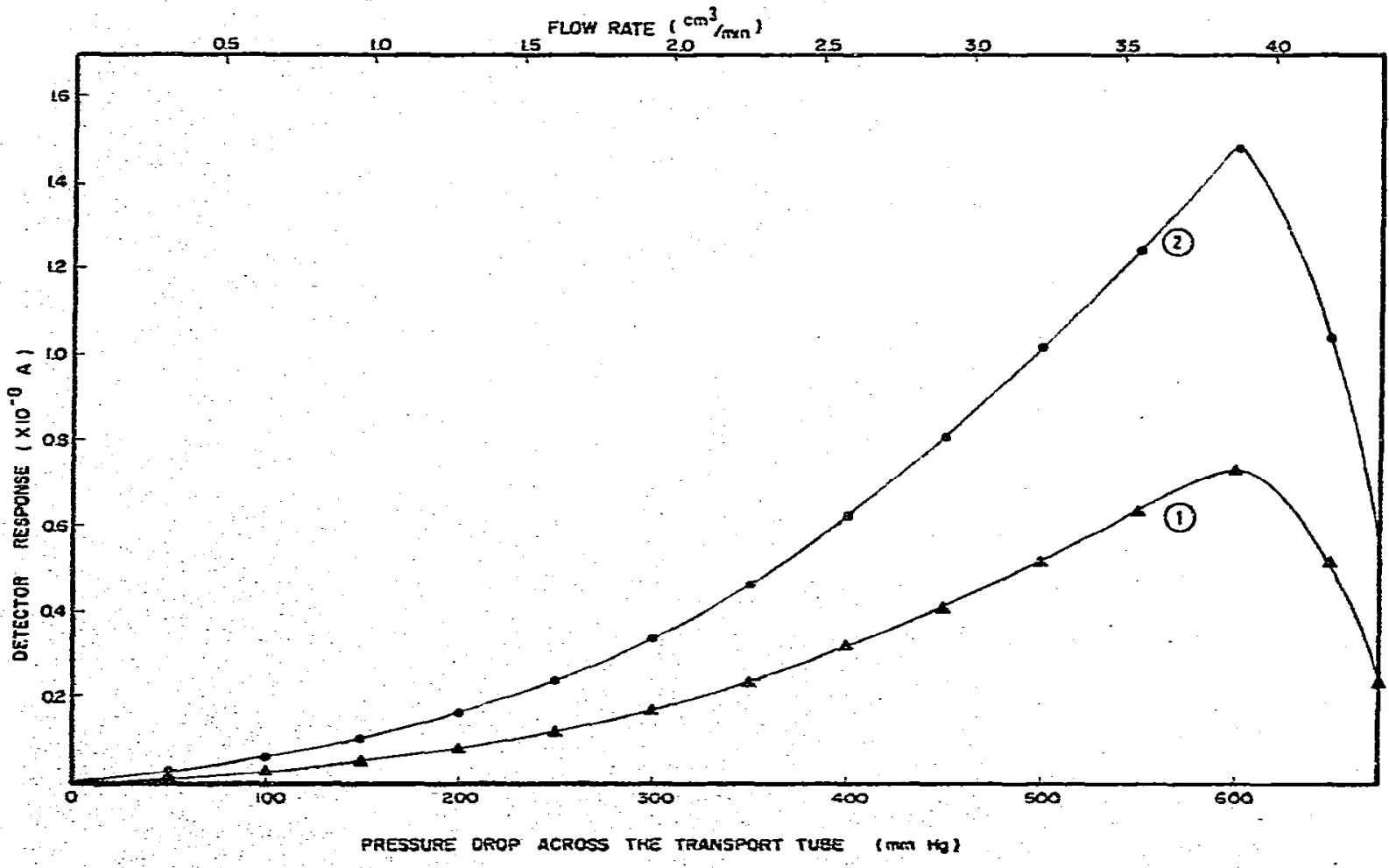

Fig 3. Fressure drop dependence of the detector response. Curves 1 and 2 correspond to diethyl ether concentrations in air of 0.6 and $1.2 \%(v / v)$, respectively. 
$H$ (height equivalent to a theoretical plate, $m$ ) is a measure of peak broadening. The standard deviation, $\sigma(\mathrm{sec})$, of the Gaussian function is given by

$$
\sigma=\frac{1}{\bar{v}} \sqrt{L H}
$$

In order to obtain an impression of the order of magnitude, the standard deviation, $\sigma$, is calculated below for a diethyl ether-air mixture at $\Delta p=600 \mathrm{~mm} \mathrm{Hg}(\bar{v}=$ $1.33 \mathrm{~m} / \mathrm{sec}$ ). The diffusion coefficient, $D_{\xi}$, of diethyl ether in air is approximated by the equation of Gilliland ${ }^{7}$ :

$$
D_{g}=4.3 \cdot 10^{-7} \cdot \frac{T^{3 / 2}}{\bar{p}\left[V_{1}^{1 / 3}+V_{2}^{1 / 3}\right]^{2}} \cdot\left(\frac{1}{M_{1}}+\frac{1}{M_{2}}\right)
$$

where

$T=$ temperature of the capillary tube $\left(=313^{\circ} \mathrm{K}\right)$

$\bar{p}=$ average pressure in the tube $(=0.69 \mathrm{~atm})(\Delta p=600 \mathrm{~mm} \mathrm{Hg})$ :

$M_{1}=$ mol. wt. of air $(=28.8 \mathrm{~g} / \mathrm{mole})$;

$M_{2}=$ mol. wt. of diethyl ether (=74.1 g/mole);

$V_{1}=$ molar volume of air at b.p. $\left(=29.9 \mathrm{~cm}^{3} /\right.$ mole $)$

$V_{2}=$ molar volume of ether at b.p. $\left(=107.2 \mathrm{~cm}^{3} / \mathrm{mole}\right)$.

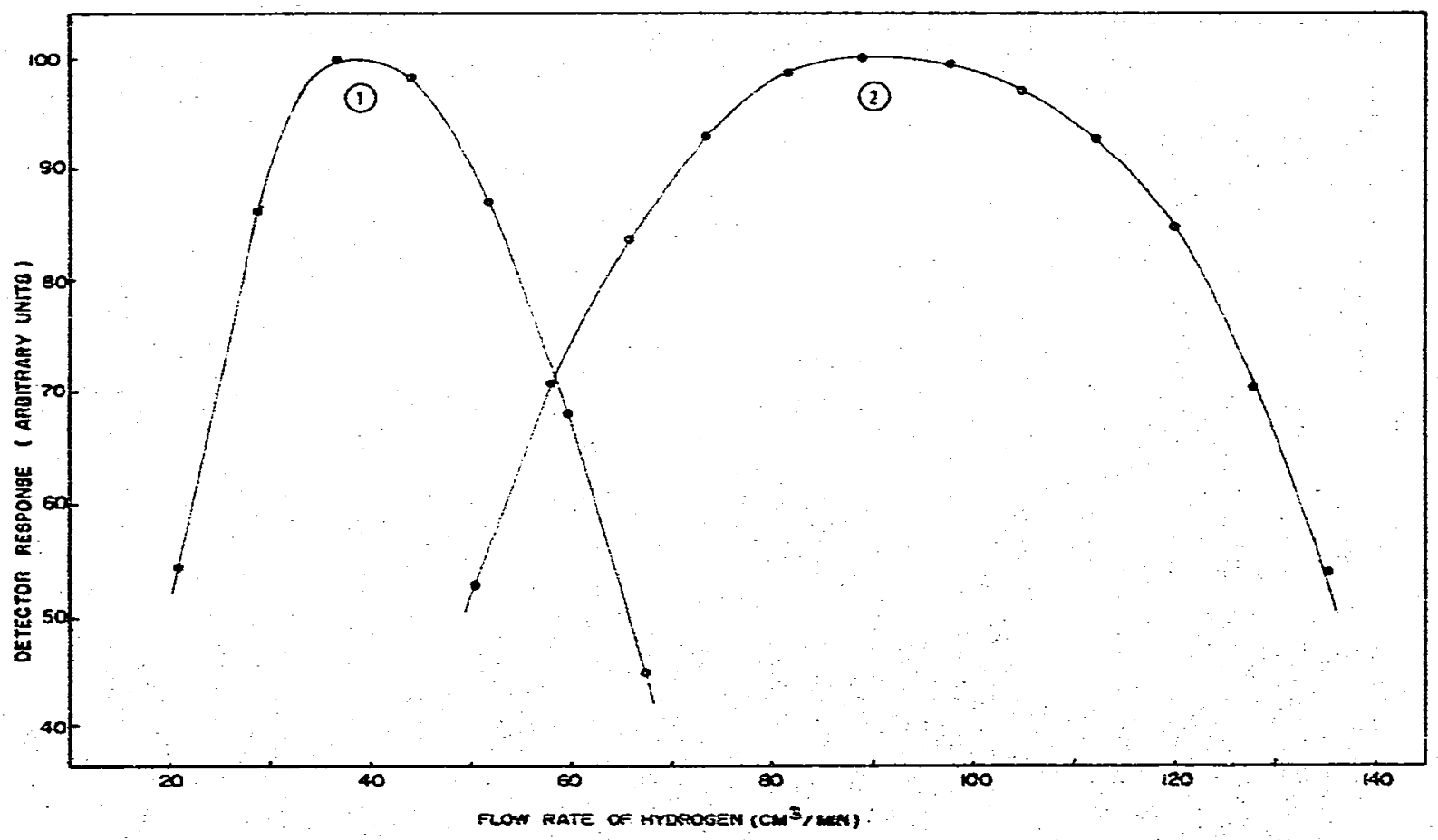

Fig. 4. Dependence of the ionization efficiency on the flow-rate of hydrogen. For both curves, the diethyl ether concentration in air is $0.5 \%(\mathrm{v} / \mathrm{v}) .1,4 p=300 \mathrm{~mm} \mathrm{Hg}$, flow-rate of air $600 \mathrm{~cm}^{3} / \mathrm{min}^{-}$; 2. $A_{p}=600 \mathrm{~mm} \mathrm{Hg}$, flow-rate of air $=950 \mathrm{~cm}^{3} / \mathrm{min}$. 


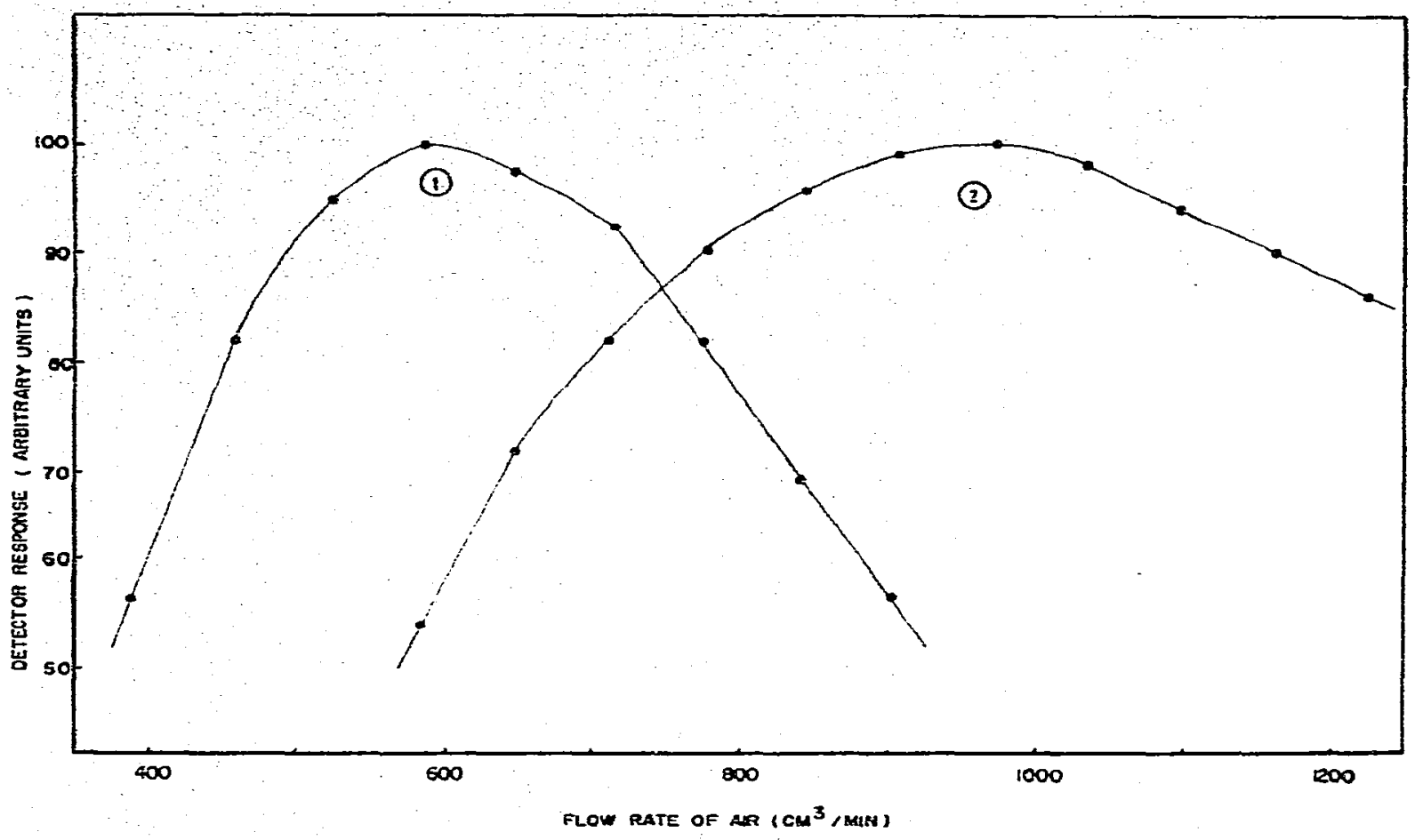

Fig. 5. Dependence of the ionization efficiency on the flow-rate of air. For toth curves, the concentration of diethyl ether in air is $0.5 \%(\mathrm{v} / \mathrm{v}) .1, \Delta p=300 \mathrm{~mm} \mathrm{Hg}$, flow-rate of hydrogen $=40 \mathrm{~cm}^{3} / \mathrm{min}$; $2, A_{p}=600 \mathrm{~mm} \mathrm{Hg}$, flow-rate of hydrogen $=90 \mathrm{~cm}^{3} / \mathrm{min}$.

It follows that $D_{g}=1.23 \cdot 10^{-5} \mathrm{~m}^{2} / \mathrm{sec}$ and thus $H=8.90 \cdot 10^{-5} \mathrm{~m}$ and $\sigma=1.69 \cdot 10^{-2}$ sec. The residence time in the tube is $4.3 \mathrm{sec}$.

It appears from this calculation that peak broadening by mixing is negligible. However, during experiments with diethyl ether, it was observed that the detector response as a function of time was an asymmetric peak with a standard deviation of the order of seconds, although a delta function was injected at the inlet of the transport tube. This effect was explained by adsorption of diethyl ether on the wall of the stainless-steel tube.

Adsorption was reduced by two means. Firstly, the tube was coated with a surfactant, benzyltriphenylphosphonium chloride, which attaches very strongly to the metal wall and covers active spots completely. Techniques for deactivating capillary columns were described by Rutten and Luyten ${ }^{8}$. Secondly, the adsorption of anaesthetic is also decreased by water vapour exhaled by the patient. Owing to its high dipole moment, water is adsorbed more strongly.

\section{Flow-rates of hydrogen and air}

Whether the flame keeps burning at reduced pressure or not depends on the flow-rates of hydrogen, air and respiratory gas. With a ratio of flow-rates of hydrogen to air of 1:10, the fiame is extinguished only at an absolute pressure less than $60 \mathrm{~mm}$ $\mathrm{Hg}$ in the detector. 
An FID at norrual pressure shows an optimum in the relationship between signal and hydrogen flow-rate (other parameters being kept constant). The same maximum is observed at reduced pressure (Fig. 4). At lower pressures, the optimum moves to higher hydrogen flow-rates (expressed in $\mathrm{cm}^{3} / \mathrm{min}$ at atmospheric pressure). Under atmospheric conditions, the detector response increases with increasing air flow-rate until a constant value is reached. In this work, however, the FID at reduced pressure shows no plateau (Fig. 5), owing to a lack of capacity of the vacuum pump used such that air flow-rates above $700 \mathrm{~cm}^{3} / \mathrm{min}$ are not adequately removed. The result is a decrease in pressure drop across the capillary tube and therefore a decrease in mass flow-rate to the detector.

\section{Calibration of the detector}

In order to check the linearity of the analyzer, a calibration graph was constructed. Standard gas mixtures were prepared in the higher concentration range by injection of known volumes of liquid anaesthetic in a 2-1 bottle provided with a serum cap. Aliquots of these gas samples were transferred to similar calibration bottles in order to produce mixtures in the parts per million range. The concentration of vapour was calculated by means of the ideal gas law. The result of a calibration with diethyl ether is shown in Fig. 6. At higher concentrations, the signal increases at a rate that is more than proportional to the increase in concentration. The FID is a mass flow detector and obviously the gas flow-rate is dependent on the concentration of diethyl ether.

Two parameters in Poisseuille's law (eqn. 1) influence the velocity in a capillary tube with fixed dimensions: the pressure drop, $\Delta p$, and the dynamic viscosity, $\eta$, both of which play a role in the determination of the calibration graph. If the concentration of diethyl ether is increased, the vapour pressure in the bottle increases. Thus the pressure at the inlet of the tube and therefore $A p$ increase.

The viscosity of a gas mixture changes with its composition. At normal pressure and temperature, the viscosity of a diethyl ether-air mixture is as given by Herning and Zipperer':

$$
\eta=\frac{\eta_{1} y_{1} M_{1}^{\frac{1}{2}}+\eta_{2} y_{2} M_{2}^{\frac{1}{2}}}{y_{1} M_{1}^{\frac{1}{2}}+y_{2} M_{2}^{\frac{1}{2}}}
$$

where

$\eta_{1}=$ viscosity of diethyl ether (vapour) $\left(=0.738 \cdot 10^{-5} \mathrm{~N} \cdot \mathrm{sec} / \mathrm{m}^{2}\right)$

$\eta_{2}=$ viscosity of air $\left(=1.861 \cdot 10^{-5} \mathrm{~N} \cdot \mathrm{sec} / \mathrm{m}^{2}\right)$

$M_{1}$ and $M_{2}=$ mol. wts. of diethyl ether and air, respectively $(\mathrm{g} / \mathrm{mole})$;

$y_{1}$ and $y_{2}=$ molar fractions of ether and air, respectively.

The viscosity of a diethyl ether-air mixture decreases with increasing concentration of diethyl ether. According to Poisseuille's law, both an increasing pressure drop and a decreasing viscosity result in an increasing linear velocity, $\bar{v}$. After correction for both of these effects, the calibration graph appears to be linear (Fig 6). Obviously, the correction for $\Delta p$ is due to the calibration procedure used. In Fig. 7 a similar graph for halothane is given. 


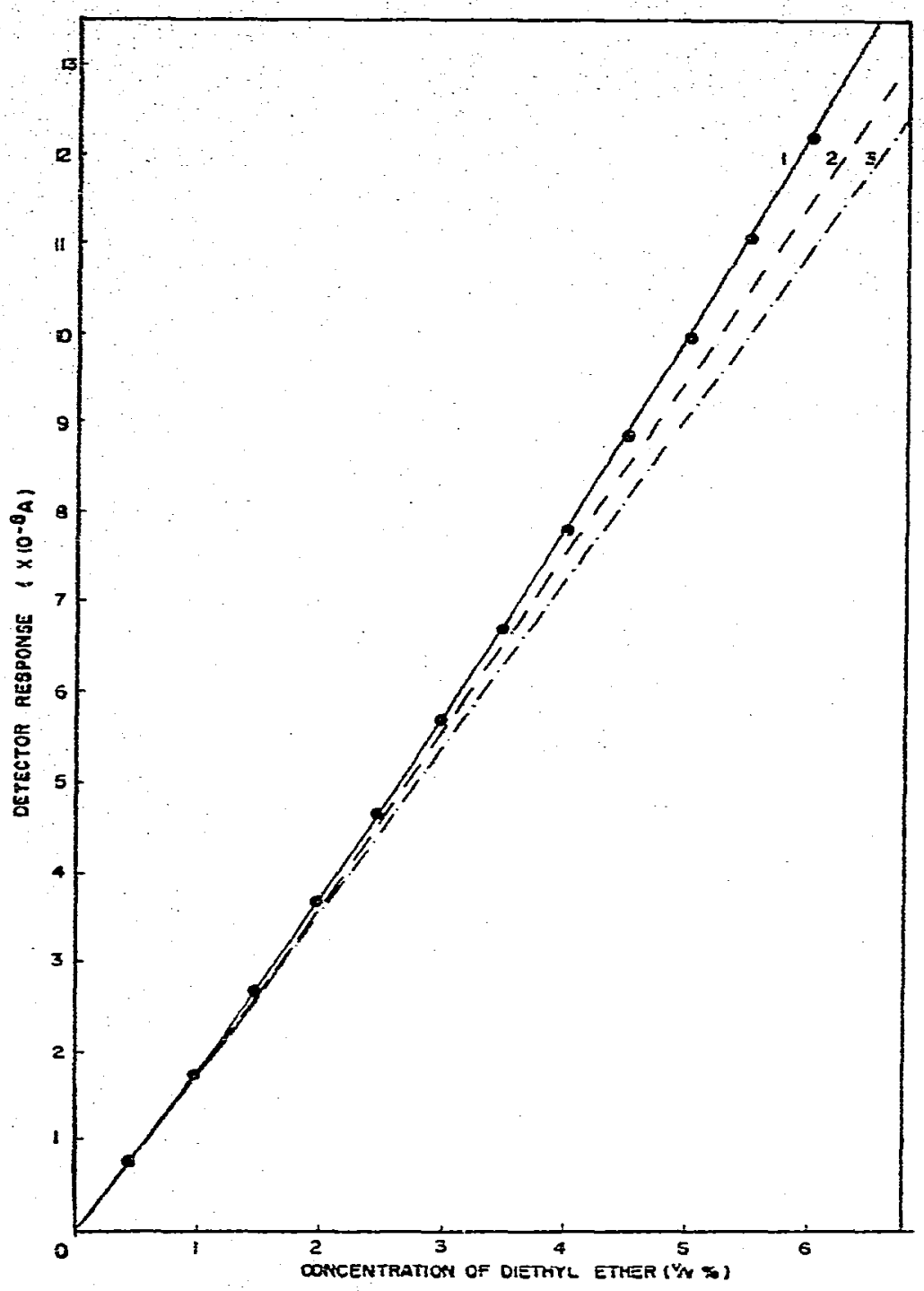

Fig. 6. Calibration graph for the FID for diethyl ether. $4 p=600 \mathrm{~mm} \mathrm{Hg}$; fiow-rate of hydrogen $=$ $85 \mathrm{~cm}^{3} / \mathrm{min}$; flow-rate of air $=900 \mathrm{~cm}^{3} / \mathrm{min}$. 1, Measured curve; 2 , curve corrected for change in pressure drop, $J p ; 3$, curve also corrected for change in dynamic viscosity, $\eta$.

\section{APPLICATIONS}

So far, the analyzer described has been tested in practice in connection with two research projects. The project at the Catholic University of Nijmegen comprises anaesthesia using an intravenous infusion of diethyl ether ${ }^{10}$, and the other project is a determination of the ventilation:perfusion ratio in the lungs, being carried out at the Institute of Medical Physics, T.N.O., in Utrecht ${ }^{11}$. A few diagrams produced by the anaiyzer during these investigations will be given here. 


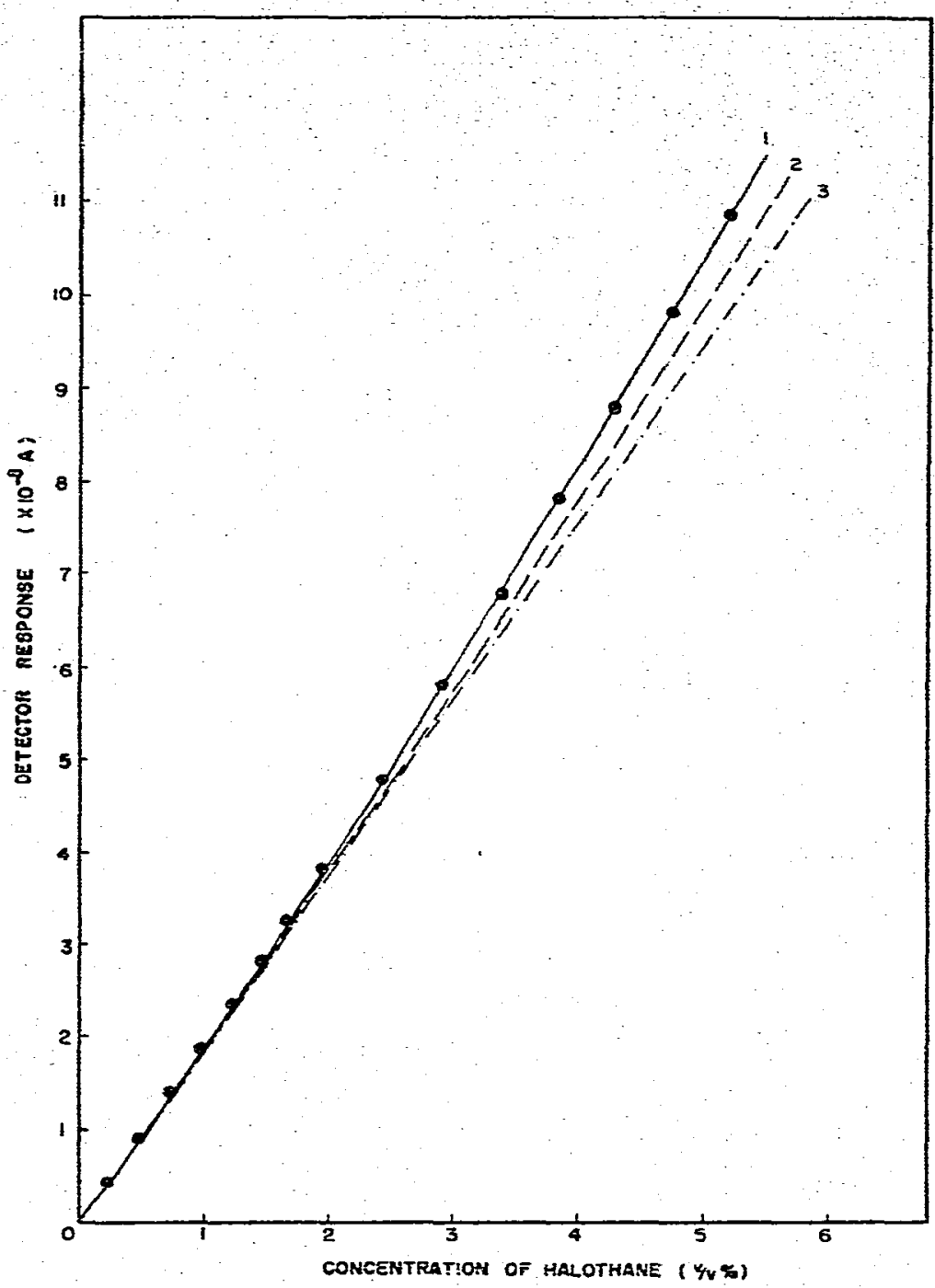

Fig. 7. Calibration graph for the FID for halothane. $A p=600 \mathrm{~mm} \mathrm{Hg}$; flow-rate of hydrogen $=$ $85 \mathrm{~cm}^{3} / \mathrm{min}$; flow-rate of air $=900 \mathrm{~cm}^{3} / \mathrm{min}$. 1 , Measured curve; 2 , curve corrected for change in pressure drop, $\Delta_{p} ; 3$, curve also corrected for change in dynamic viscosity, $\eta$.

As mentioned in the previous section, the only parameter needed to determine the velocity, $\vec{v}$, in the transport tube is the pressure in the FID if definite tube dimensions are selected (I.D. $0.25 \mathrm{~mm}$, length $5.7 \mathrm{~m}$ ). In the experiments, the pressure drop across the capillary tube was chosen as $600 \mathrm{~mm} \mathrm{Hg}$ in order to reduce the time lag between sampling and detection. Also, the signal-to-noise ratio is favourable at this pressure difference. The optimal flow-rates of hydrogen and air used can be seen from Figs: 4 and 5.

Zwart et al. ${ }^{10}$ demonstrated that there is a relationship between the arterial concentration of the anaesthetic agent and its concentration in end-tidal air. Both 
ONLINE ANALYZER FOR ORGANIC ANAESTHETICS

81

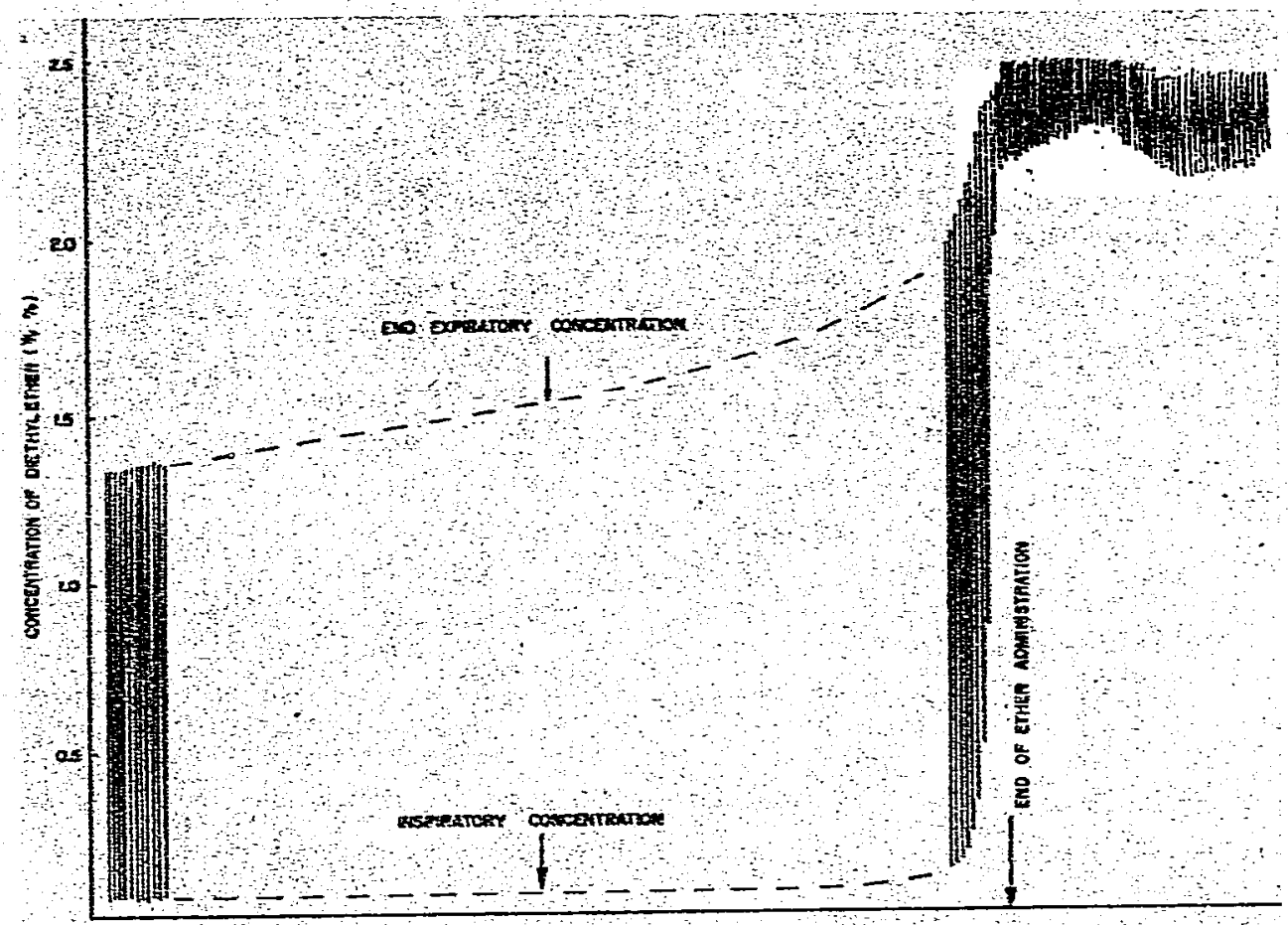

Fig. 8. First part of the washout curve after a combined intravenous infusion-inhalation diethyl ether anaesthesia.

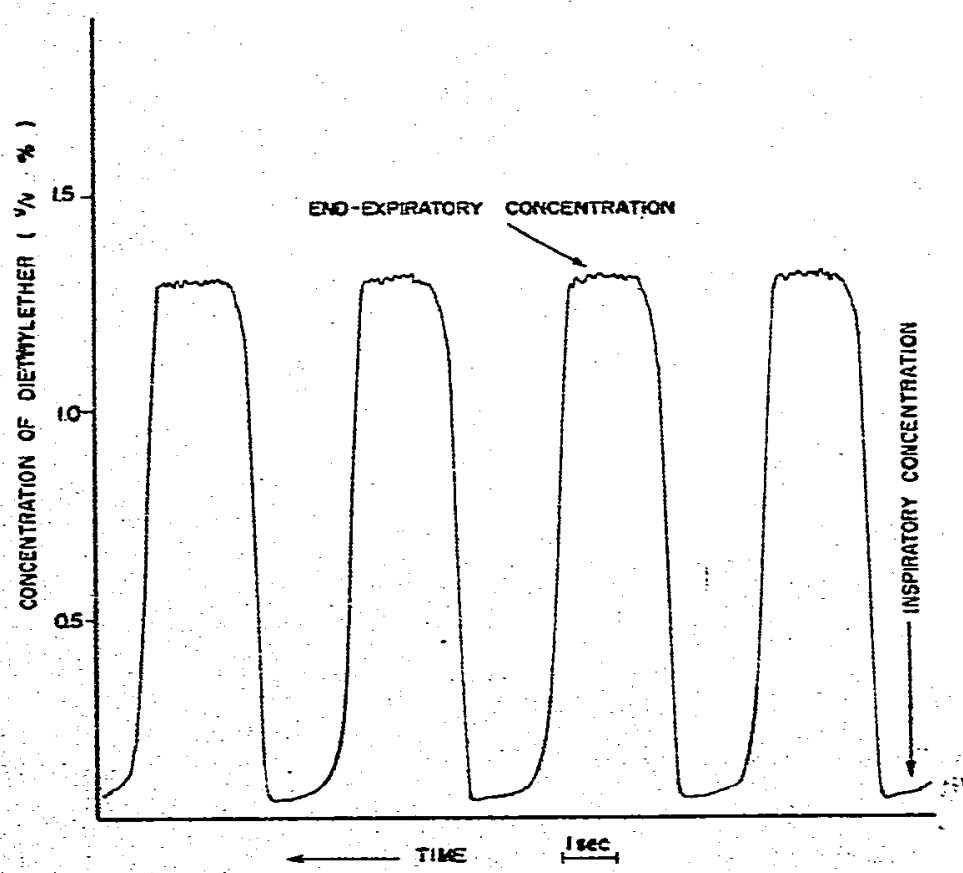

Fig. 9. Respiration during the diethyl ether washout, recorded at maximum chart speed. 
concentrations show a similar course during anaesthesia. Fig. 8 illustrates part of the wash-out curve after a combined ether infusion-inhalation anaesthesia. The respiration of the dog anaesthetized was controlled with a ventilator. During the administration of diethyl ether, the inspiratory concentration showed variations, caused by the on-off control of the vaporizer heater. After both the inhalation and infusion of diethyl ether was stopped, the amount inspired quickly approached zero. The inspiratory concentration does not reach zero completely, because the vaporizer and rubber connection tubes subsequently deliver ether. The expiratory concentration is described by a bi-exponential curve ${ }^{10}$. From this curve, a few respirations are shown in Fig. 9, recorded at maximum chart speed. Owing to the controlled ventilation, the respirations are reproducible with time. It appears that the "alveoiar plateau" is reached during an expiration and therefore the end-tidal concentration is measured correctly. The small fluctuations in the end-expiratory concentration may be caused by the heart rate.

During experiments to determine the ventilation:perfusion ratio, small amounts of halothane were administered to a test person. For reasons discussed by Zwart et al. ${ }^{11}$, the inspiratory concentration is varied according to two sine functions, and therefore the inpat functions of the valve system in the inspiratory supply line

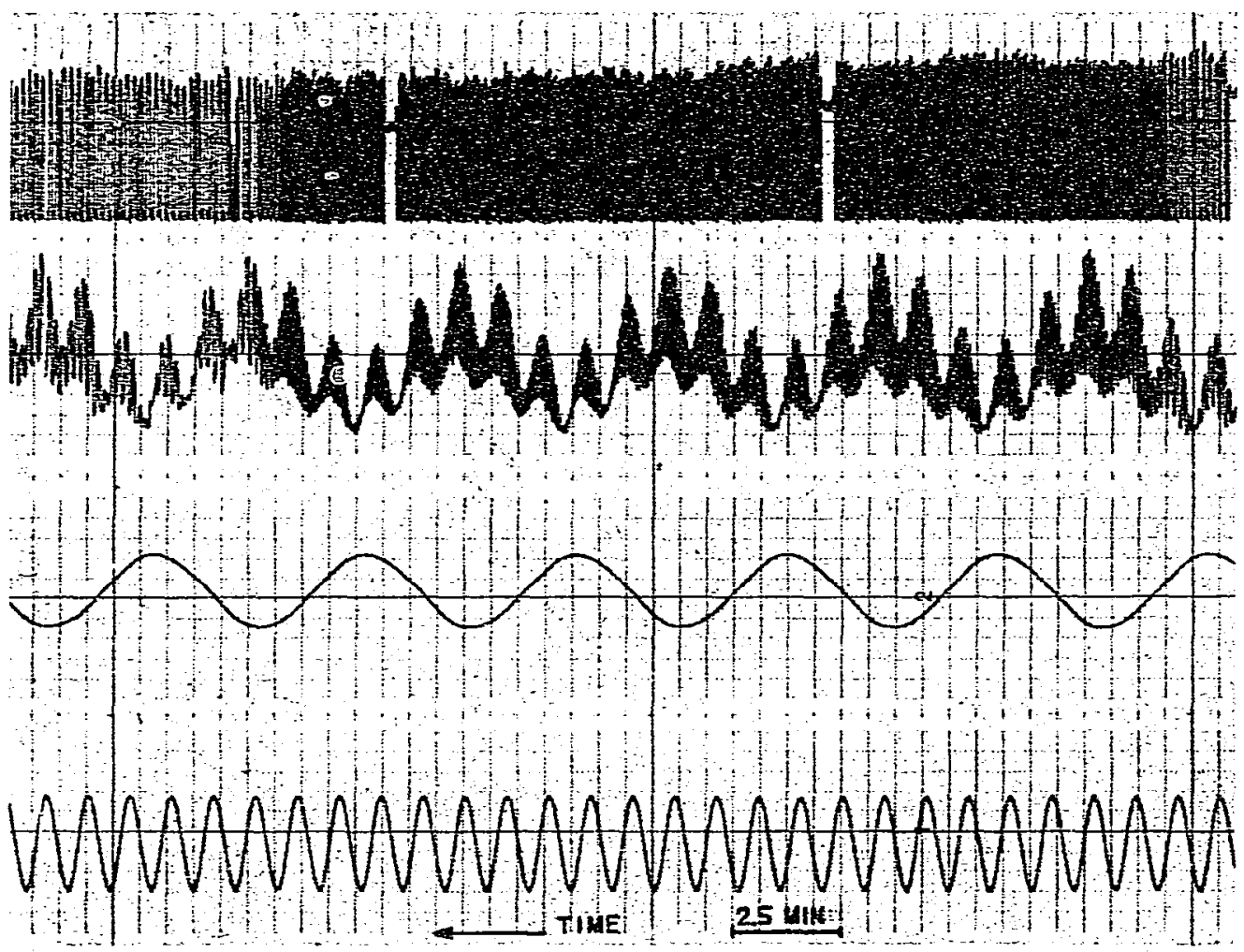

Fig. 10. Inspiratory halothane concentration varied according to two sine functions with periodic times 36 and $180 \mathrm{sec}$ and amplitude $0.02 \%$ (v/v). From bottom upwards: separate sine waves; inspiratory and end-tidal halothane concentrations, monitored by the on-line analyzer; and the inspiratory and expiratory carbon dioxide percentages. 
are modulated with a sine generator. The two functions have different periodic times: 36 and $180 \mathrm{sec}$. The amplitude is $0.02 \%(\mathrm{v} / \mathrm{v})$, the minimum and maximum being 0.01 and $0.03 \%(v / v)$, respectively. Thus inspiratory halothane concentrations are far below the anaesthetic action level. Fig. 10 shows the input functions of the valve system (recorded signals from the generator), the inspiratory and expiratory concentrations, measured by the on-line analyzer described in this paper, and the carbon dioxide concentration. The recordings show that the sine functions can be identified in the patterns of both inspiratory and expiratory concentrations. The different respiration frequencies can be clearly distinguished.

As mentioned above, it is possible to monitor very small concentrations of anaesthetic agent in a gas phase on account of the high sensitivity of the detector. This makes the instrument also applicable to the measurement of the concentration of an anaesthetic in blood, if the anaesthetic is extracted from a blood sample by means of a headspace technique. The anaesthetic agent is released by shaking a small volume of blood in a relatively large flask, closed with a serum cap. After equilibration, the concentration in the gas phase is determined. The original blood level can be calculated if the blood-gas partition coefficient of the anaesthetic concerned is known ${ }^{1}$. The concentration in the gas phase can be measured by inserting the needle at the end of the capillary transport tube through the serum cap. Results of such measurements were given by Zwart et al. ${ }^{10}$.

\section{DISCUSSION}

It has been shown that, although the FID operates in the linear dynamic range, the increase in the signal is more than proportional to the increase in anaesthetic concentration in calibration mixtures. This phenomenon was explained by the influence of both the pressure drop, $\Delta p$, across the capillary tube and the dynamic viscosity of the mixture on the linear velocity, $\bar{v}$. During measurements of inspiratory and end-tidal concentrations of an anaesthetized patient, the pressure drop can be considered to be constant; the pressure at the transport tube inlet in the endotracheai tube varies only slightly during respiration; this effect on the velocity can be neglected.

During wash-in procedures, the composition of the expiration gas changes gradually. Owing to different uptake rates, the percentages of both the organic anaesthetic agent and the inorganic components change, until a constant gas composition is reached. Thus during anaesthesia, the viscosity of the expired gas is not constant and therefore the linear velocity in the capillary tube varies. The accuracy of the measurement of end-tidal concentrations is dependent on the composition of the expiration gas.

It is possible to calculate the viscosity of expiratory gas by means of an extension of eqn. 5 :

$$
\eta=\frac{\sum_{i} \eta_{i} y_{i} M_{i}^{\frac{1}{2}}}{\sum_{i} y_{i} M_{i}^{\frac{1}{2}}}
$$

This equation applies to all components that appear in the respiratory gas of an anaesthetized patient. 
The order of magnitude of the "viscosity effect" was obtained by calculating the effect of different viscosities of expiratory gas on the linear velocity, $\bar{v}$, at different times during anaesthesia. In this way, deviations of measured concentrations from actual concentrations expired can be determined. Using an inspiratory gas mixture of oxygen and nitrous oxide (1:2), containing $5 \%(\mathrm{v} / \mathrm{v})$ of diethyl ether as reference, deviations of from $-8 \%$ were calculated, i.e., the measured value was $92 \%$ of the actual concentration, at the start of administration of the anaesthetic gases, up to $+3 \%$, when the inspiratory and end-tidal anaesthetic concentrations were equal. The deviation of $-8 \%$ at the beginning is caused by a lack of nitrous oxide in the expiratory gas in comparison with the inhaled gas. Within a short period, however, the percentage of nitrous oxide expired approaches the content in the inspiratory gas. In this period, the deviation decreases from -8 to $-3 \%$. The deviation of $+3 \%$ at equal inspiratory and expiratory anaesthetic concentrations is caused by the different contents of oxygen, carbon dioxide and water vapour in the inspiratory and endtidal gases. If the calibration mixture does not have the same composition as the inhalation gas (e.g., a diethyl ether-air mixture), the deviations will be greater.

In using the analyzer, one should bear in mind that its response is a function of the total organic content of the expiratory gas. Therefore, only one anaesthetic can be used at a time. Care should be taken in the case of ethanol intoxication.

A commercial version of the analyzer described in this paper will be available from W.T.I., 's-Gravezande, The Netherlands.

\section{ACKNOWLEDGEMENTS}

The authors gratefully acknowledge valuable cooperation with the Department of Anaesthesiology of the Catholic University of Nijmegen (Head, Prof. Dr. J. F. Crul) and the Department of Anaesthesiology of the St. Liduina Hospital in Boxtel (Head, Dr. R. Garciá Martinez). Special gratitude is due to the Group of Cardio Vascular Physics of the Institute of Medical Physics, T.N.O., in Utrecht (A: Zwart) for the application of the analyzer in their research programme.

\section{REFERENCES}

1 H. Beneken Kolmer, A. Burm, C. Cramers, J. Ramakers and H. Vader, Brit. J. Anaesth., 47 (1975) $1049,1169$.

$2 \dot{R}$. Porter (Eaitor), Gas Chromatography in Biology and Medicine, Churchill. London, 1969.

3 R. Feinland, A. J. Andreatch and D. P. Cotrupe, Anal. Chem., 33 (1961) 991.

4 P. Boček, J. Novák and J. Janák, J. Chromatogr., 48 (1970) 412.

5 P. Boček, J. Novák and J. Janák, J. Chromarogr. Sci., 8 (1970) 226.

G M. Golay, in D. H. Desty (Editor), Gas Chromatography, Butterworths, London, 1st ed., 1958, p. 36.

7 E. R. Gilliland, Ind. Eng. Chem., 26 (1934) 681.

8 G. A. F. M. Rutten ard J. A. Luyten, J. Chromatogr., 74 (1972) 177.

9 F. Herning and L. Zipperer, Gas Wasserfach, 79 (1936) 49 and 69.

10 A. Zwart, L. de Leeuw, A. van Dieren, T. Vree, S. Saleh, R. Garciá Martinez and H. Trimbos, Brit. J. Anaesth., 48 (1976) in press.

11 A. Zwart, R. Seagrave and A. van Dieren, J. Appl. Physiol., (1976) in press. 